\title{
Pemanfaatan Teknologi Informasi untuk Pembaruan Peta Sarana Desa di Desa Pemagarsari, Parung, Bogor
}

\author{
Eko Hadi Purwanto ${ }^{1}$, Arief Goeritno ${ }^{2}$ \\ 1, 2 Universitas Ibn Khaldun Bogor
}

\begin{abstract}
Article History ABSTRACT
Received 08.07.2019

Received in revised form 10.09.2019

Accepted 05.10.2019

Available online 28.10.2019

UTILIZATION OF INFORMATION TECHNOLOGY FOR UPDATING THE MAP OF VILLAGE FACILITIES IN DESA PEMAGARSARI, PARUNG, BOGOR. A work program to support the updating of the map of village facilities by a number of students belonging to the Group 13 of KKN-TT from Bogor Ibn Khaldun University in Desa Pemagarsari, Parung, Bogor. The process of updating the map of village facilities is in the form of social interaction between students belonging to the Group 13 of KKN-TT Bogor Ibn Khaldun University in 2017 with the target community represented by the staffs of Desa Pemagarsari. This paper aims to convey information about a number of stages for the process of updating \& the physical form of updated for the map of village facilities. This paper aims to convey information about a number of stages for the process of updating \& the physical form of updated the map of village facilities. A number of stages for the process of updating the map of village facilities, including the preparation of the work team, submission of renewal permits for the map of village facilities, \& comparison of secondary \& primary data. The physical form of an updated the map of village facilities is a process of renewing \& making hardcopy of the map of village facilities of A1 paper size along with a frame \& scheduling \& submission of a symbolic the map of village facilities to the Head for Desa Pemagarsari.

KEYWORDS: Map of Village Facilities, Pemagarsari, Utilization of Information Technology.
\end{abstract} Attribution 4.0 International License, which permits unrestricted use, distribution, and reproduction in any medium, provided the original work is properly cited. (c) 2019 Eko Hadi Purwanto, Arief Goeritno.

\section{PENDAHULUAN}

Istilah Teknologi Informasi (TI) atau dalam bahasa Inggris dikenal dengan Information Technology (IT) dengan pengertian modern, pertama kali dimunculkan dalam sebuah artikel pada tahun 1958 dalam Harvard Business Review dengan para penulis Harold J. Leavitt dan Thomas L. Whisler dengan komentar (Leavitt \& Whisler, 1958), bahwa teknologi informasi merupakan teknologi baru belum dengan nama tunggal yang disematkan, tetapi disebut dengan teknologi informasi (Leavitt \& Whisler, 1958;

${ }^{2}$ Corresponding author: Program Studi Teknik Elektro, Universitas Ibn Khaldun Bogor; Jl. K.H. Sholeh Iskandar km.2, Kedung Badak, Tanah Sareal, Kota Bogor, Jawa Barat; Email: arief.goeritno@uika-bogor.ac.id 
Applegate et al, 1988). Teknologi Informasi (TI) merupakan istilah umum untuk keberadaan teknologi apa pun guna perbantuan ke manusia dalam pembuatan, pengubahan, penyimpanan, pengkomunikasian, dan/atau penyebarluasan informasi (Williams \& Sawyer, 2014). Teknologi informasi sebagai penyatu komputasi dan komunikasi berkecepatan tinggi untuk data, suara, dan video (Williams \& Sawyer, 2007). Dalam konteks bisnis dijelaskan oleh Information Technology Association of America (ITAA), bahwa teknologi informasi merupakan pengolahan, penyimpanan, dan penyebaran vokal, informasi bergambar, teks dan numerik oleh mikroelektronika berbasis kombinasi komputasi dan telekomunikasi (Longley \& Shain, 1988). Contoh pemanfaatan teknologi informasi bukan hanya berupa komputer pribadi, tetapi juga telepon, televisi, peralatan elektronika rumah tangga, dan peranti genggam modern, dalam hal ini telepon selular atau ponsel (Williams \& Sawyer, 2014). Beberapa bidang modern dimunculkan dari teknologi informasi sebagai generasi berikutnya, yaitu teknologi web, bioinformatika, cloud computing, sistem informasi global, skala besar basis pengetahuan, dan lain-lain (Simpson \& Weiner, 1989; Williams \& Sawyer, 2014).

Peta dikenal juga dengan denah, merupakan kata benda dengan makna representasi melalui gambar dari suatu daerah dengan pernyataan sifat, seperti batas daerah, sifat permukaan, atau lainnya (Pusat Bahasa Departemen Pendidikan Nasional, 2008) atau suatu gambaran dari unsur-unsur alam dan atau buatan manusia, yang berada di atas maupun di bawah permukaan bumi yang digambarkan pada suatu bidang datar dengan skala tertentu (PP Nomor 8, 2013). Peta Dasar adalah Peta dengan penyajian unsur-unsur alam dan/atau buatan manusia yang berada di permukaan bumi, digambarkan pada suatu bidang datar dengan skala, pernomoran, proyeksi, dan georeferensi tertentu. Ketelitian Peta adalah ketepatan, kerincian dan kelengkapan data, dan/atau informasi georeferensi dan tematik, sehingga merupakan penggabungan dari sistem referensi geometris, skala, akurasi, atau kerincian basis data, format penyimpanan secara digital termasuk kode unsur, penyajian kartografis dengan cakupan simbol, warna, arsiran dan notasi, dan kelengkapan muatan peta (PP Nomor 8, 2013). Peta Sarana Desa merupakan peta wilayah saat diterapkan berdasarkan peraturan di pemerintahan desa sesuai dengan kebutuhan dan lingkup penerbitan dokumen dalam bentuk peta.

Desa Pemagarsari merupakan salah satu desa di wilayah Kecamatan Parung, Kabupaten Bogor, Provinsi Jawa Barat (Diskominfo Kabupaten Bogor, 2014) yang merupakan desa hasil pemekaran dari Desa Parung, Kecamatan Parung, pada tahun 1982 dan resmi menjadi salah satu desa di Kecamatan Parung. Kantor Desa Pemagarsari tampak depan, seperti ditunjukkan pada Gambar 1.

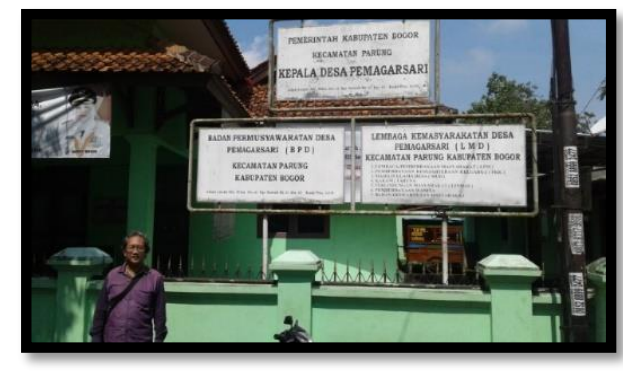

Gambar 1. Kantor Desa Pemagarsari tampak depan

Posisi Desa Pemagarsari di antara desa-desa lain di wilayah Kecamatan Parung (Diskominfo Kabupaten Bogor, 2014), seperti ditunjukkan pada Gambar 2. 


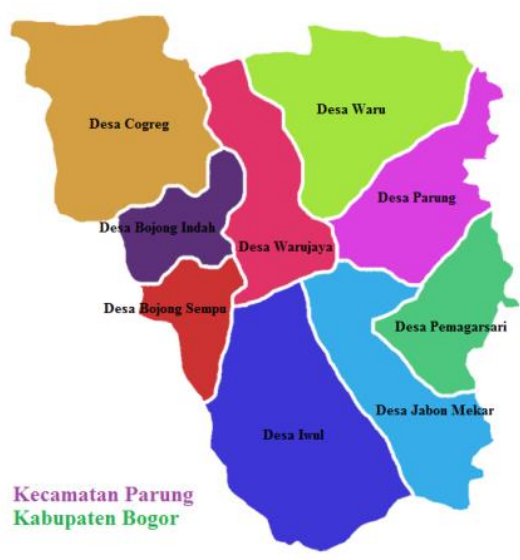

Gambar 2. Posisi Desa Pemagarsari di antara desa-desa lain di wilayah Kecamatan Parung Sumber: https://kecamatanparung.bogorkab.go.id/desa/208

Jarak pencapaian Desa Pemagarsari dari kampus Universitas Ibn Khaldun Bogor (UIKA Bogor) sepanjang 20,9 km. Tampilan jarak pencapaian lokasi Kantor Desa Pemagarsari dari kampus UIKA Bogor, seperti ditunjukkan pada Gambar 3.

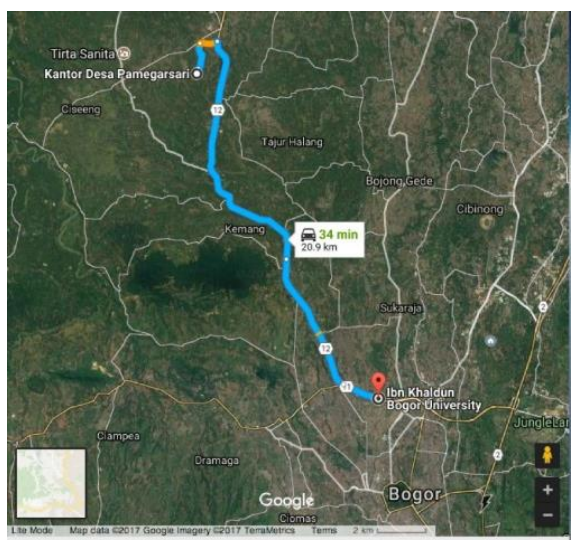

Gambar 3. Tampilan jarak pencapaian lokasi Kantor Desa Pemagarsari dari kampus UIKA Bogor

Peningkatan pembangunan manusia dipusatkan di Kantor Desa Pemagarsari sebagai pusat pemerintahan. Kantor Desa difungsikan sebagai tempat bekerja Kepala Desa berikut jajarannya, Badan Permusyawaratan Desa (BPD), dan Lembaga Masyarakat Desa (LMD). Desa Pemagarsari dengan luas wilayah sebesar 266,086 hektar (Ha.), terdiri atas 6 (enam) Rukun Warga yang masing-masing diketuai oleh seorang Ketua RW dengan jumlah keseluruhan Rukum Tetangga (RT) sebanyak 34 (tiga puluh empat). Informasi tentang profil Desa Pemagarsari, yaitu:

Batas Wilayah Desa
a) Sebelah Utara
Desa Parung, Kecamatan Parung
b) Sebelah Timur
Desa Citayam, Kecamatan Tajurhalang
c) Sebelah Selatan
Desa Jabon Mekar, Kecamatan Kemang
d) Sebelah Barat
Desa Waru Jaya , Kecamatan Parung 
Peruntukan Lahan

a) Jalan Lingkungan

b) Jalan Setapak

c) Jalan Protokol

d) Sarana dan Prasarana Umum

e) Permukiman

Kependudukan
a) Kartu Keluarga
b) Jumlah Laki-laki
c) Jumlah Perempuan
7.174 orang
3.699
7.167 orang

terbuat dari aspal

tanah

terbuat dari aspal

masjid, sekolah, pertokoan

Tingkat Pendidikan
a) $\mathrm{SD}$
b) SMP
c) SMA
d) Akademi (D1-D3)
e) Sarjana (S1-S3)
f) Pondok Pesantren
g) Madrasah
h) Tidak Sekolah

(kategori) padat penduduk

67 jiwa

Sarana
a) Masjid
11 unit
b) Mushola
30 unit
c) Gereja
d) PAUD
-
e) $\mathrm{SD}$
10 unit
5 unit
f) $\mathrm{SMP}$
2 unit
g) SMA
2 unit
h) Puskesmas
5 unit
i) Posyandu
9 unit
j) Warung Internet
5 unit
k) Kantor Pos
1 unit
1) Tempat Pemakaman Umum
5 lokasi
Organisasi Kemasyarakatan
a) PKK
1 organisasi
b) Karang Taruna
1 organisasi
c) LPM
1 organisasi
d) Dewan Keluarga Masjid
12 organisasi

Berdasarkan uraian-uraian di atas, maka dibuat program kerja untuk dukungan terhadap pembaruan peta sarana desa oleh sejumlah mahasiswa yang tergabung dalam Kelompok 13 Kuliah Kerja Nyata Tematik Terintegrasi (KKN-TT) Universitas Ibn Khaldun (UIKA) Bogor di Desa Pemagarsari, Kecamatan Parung, Kabupaten Bogor. Proses pembaruan terhadap peta sarana desa berupa interaksi sosial antara para mahasiswa yang tergabung dalam Kelompok 13 KKN-TT UIKA Bogor tahun 2017 dengan masyarakat sasaran yang diwakili oleh perangkat Desa Pemagarsari (Hikmat, 2001). Alternatif pemecahan masalah yang mungkin dilakukan, adalah melalui penerapan teknologi tepat guna, dengan teknologi tersebut harus bersifat sederhana, praktis, dan berwawasan lingkungan (Goeritno et al, 2003). Makalah ini bertujuan untuk penyampaian 
informasi tentang kegiatan para mahasiswa di kelompok 13 dalam program pokok saat pelaksanaan KKN-TT tahun 2017 yang meliputi (a) memperoleh sejumlah tahapan untuk proses pembaruan terhadap peta sarana desa dan (b) memperoleh bentuk fisik peta sarana desa terbarui.

\section{METODE PELAKSANAAN}

Pelaksanaan untuk kegiatan Kelompok 13 KKN-TT dibuat dalam tahapan yang disajikan dalam bentuk bagan alir (flow chart). Bagan alir tahapan pelaksanaan kegiatan, seperti ditunjukkan pada Gambar 4.

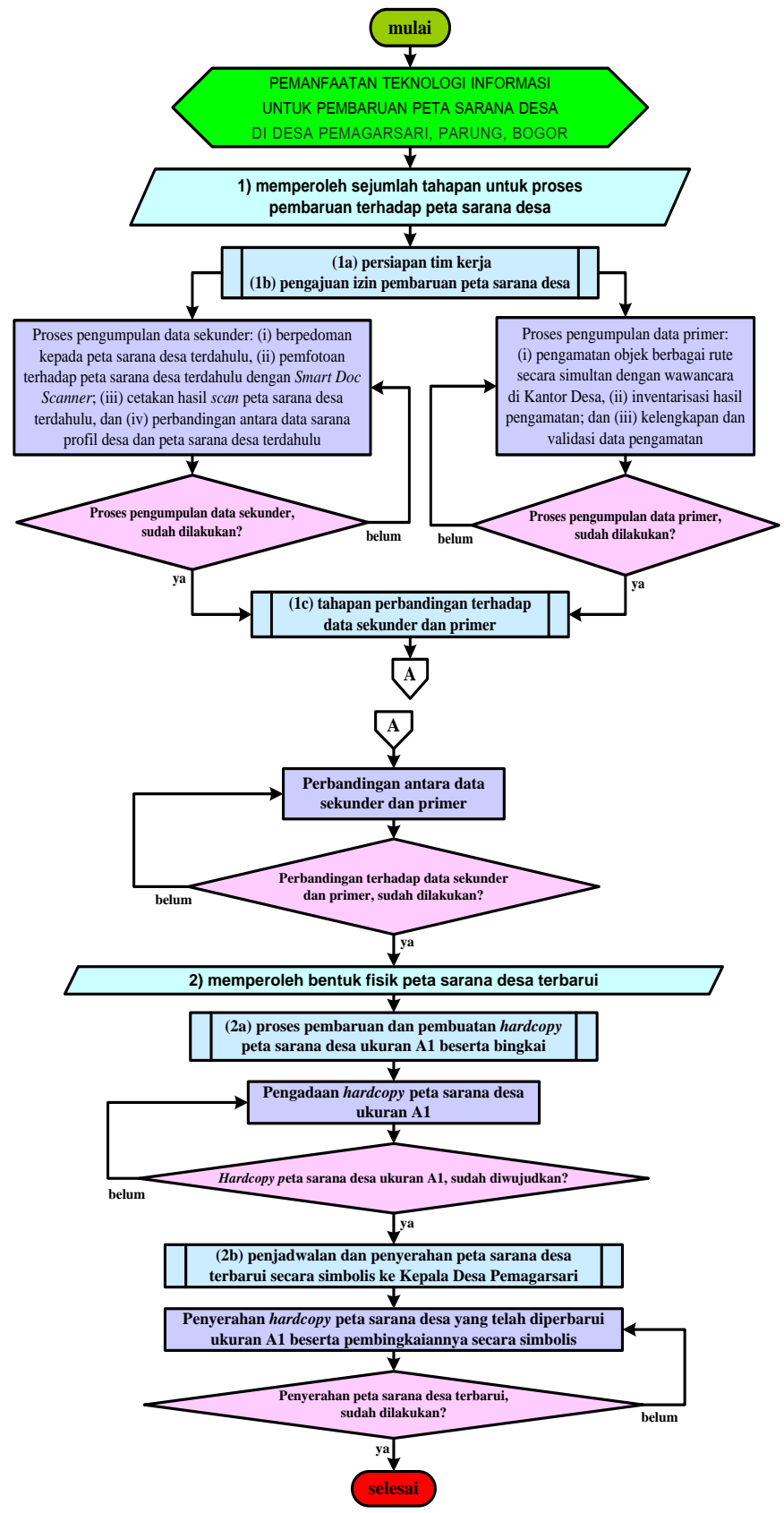

Gambar 4. Bagan alir tahapan pelaksanaan kegiatan 
Berdasarkan bagan aliran tahapan pelaksanaan kegiatan Kelompok 13 pada KKNTT tahun 2017 di Desa Pemagarsari dibuat dalam bentuk matrik. Jadwal kegiatan Kelompok 13 KKN-TT, seperti ditunjukkan pada tabel dalam Gambar 5.

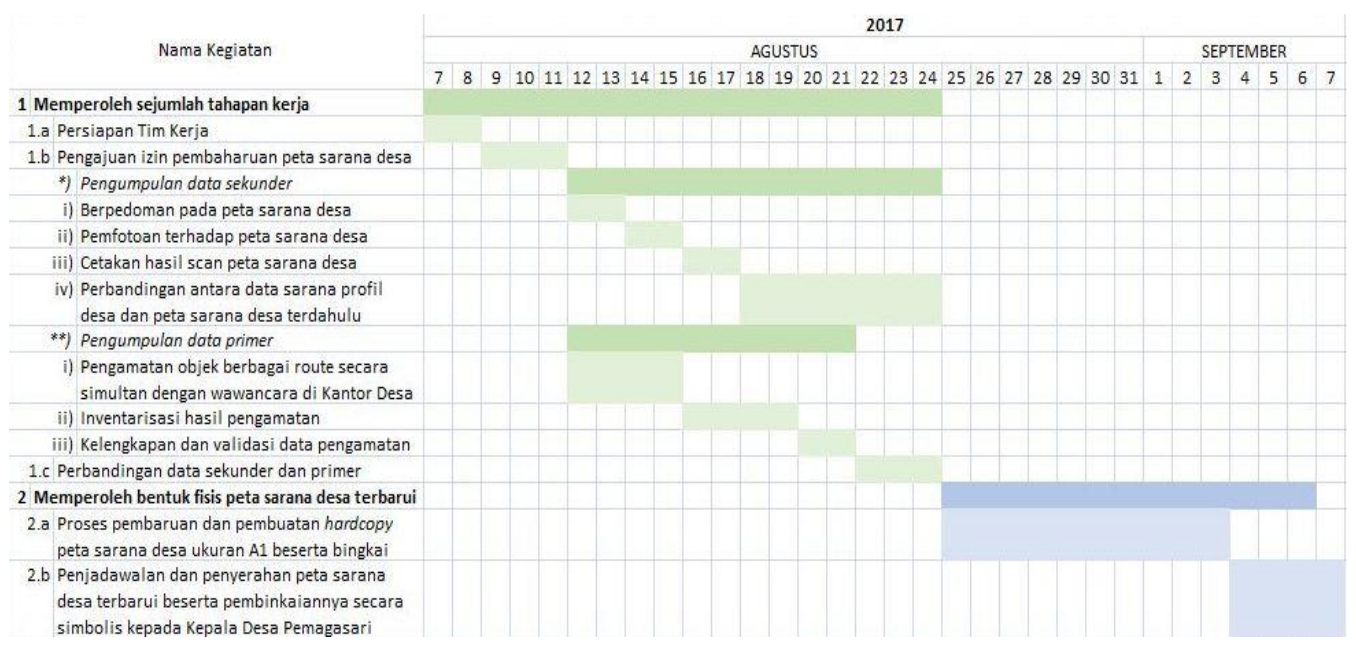

Gambar 5. Tabel Jadwal kegiatan Kelompok 13 KKN-TT

\section{HASIL DAN PEMBAHASAN}

\section{Sejumlah Tahapan Untuk Proses Pembaruan terhadap Peta Sarana Desa}

\section{Persiapan tim kerja}

Tim Pembaharuan Peta Sarana Desa Pemagarsari merupakan peserta Kelompok 13 KKN-TT UIKA tahun 2017 yang terdiri atas sejumlah mahasiswa dari berbagai program studi (prodi), yaitu:

Koordinator: Widi Hadi Prasetyo (Prodi Teknik Sipil, 141105120606);

Para Anggota:

Resha Dennistian (Prodi Ekonomi Syariah, 141104080523);

Frisca Dira Arfina (Prodi Pendidikan Bahasa Inggris, 141101010534);

Galih Arisca Dwi Putra (Prodi Manajemen, 141103040418);

Yusdiana Novitasari (Prodi Kesehatan Masyarakat, 14110610099);

Mursidin (Prodi Pendidikan Agama Islam, 141104090659);

Lestari Susilo (Prodi Pendidikan Agama Islam, 141101020434);

Destira Wijaya (Prodi Ilmu Hukum, 141102030930);

Handika Aswatama (Prodi Manajemen, 141103040395);

Abdul Hariswan (Prodi Kesehatan Masyarakat, 131106161558);

Nuraeni (Prodi Akuntansi, 141103050582);

Yusuf Mahendra (Prodi Teknik Mesin, 131105130636);

Maulana Suryana Akbar (Prodi Ekonomi Syariah, 141104081250);

Andrian Setia (Prodi Teknik Mesin, 131105130622).

Pelaksanaan pembaharuan dikoordinasi Widi Hadi Prasetyo, operator gambar dilaksanakan oleh Mursidin, dan pengamatan lapang oleh koordinator dan anggota tim 
ketika pelaksanaan tugas KKN-TT. Dosen Pembimbing Lapangan dan sejumlah anggota kelompok 13, seperti ditunjukkan pada Gambar 6.

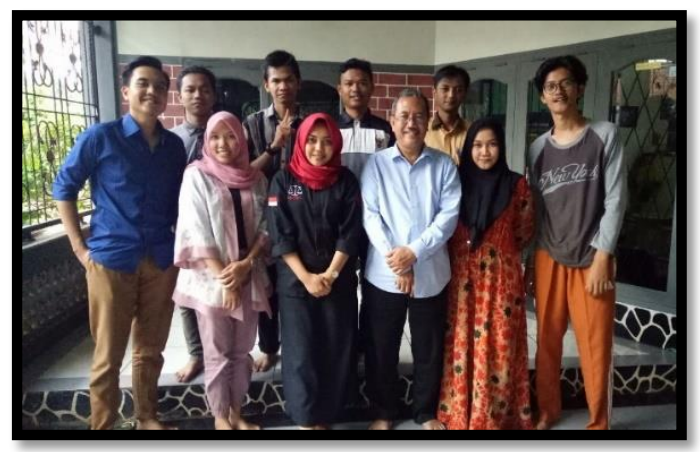

Gambar 6. Dosen Pembimbing Lapangan dan sejumlah anggota kelompok 13

\section{Pengajuan izin pembaruan peta sarana desa}

Proses pengajuan izin diawali dengan pembicaraan tentang gagasan pembaruan terhadap peta sarana desa yang ada. Tampilan peta sarana desa terdahulu, seperti ditunjukkan pada Gambar 7.

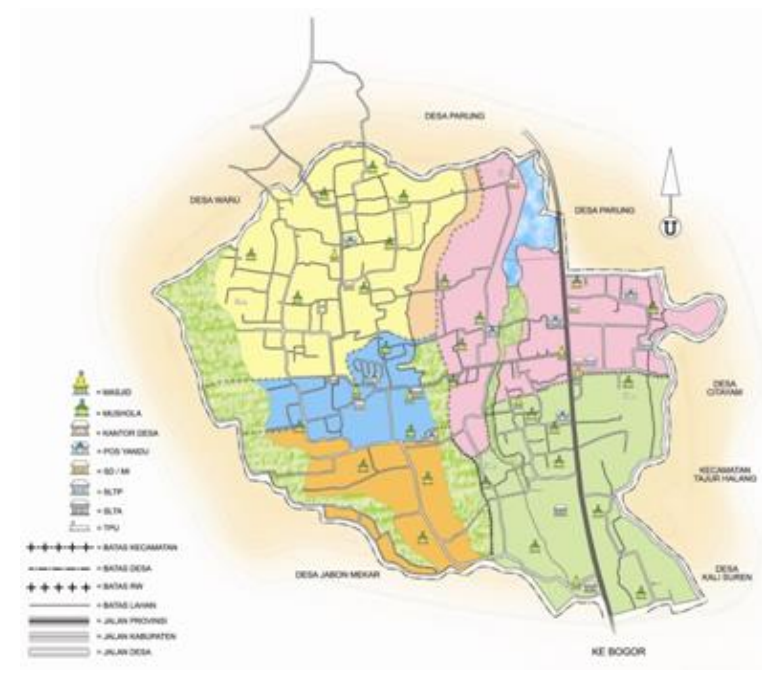

Gambar 7. Tampilan peta sarana desa terdahulu

Kepala Desa Pemagarsari antusias dalam penyambutan terhadap gagasan tersebut, sehingga hasil yang kelak diperoleh dapat dikaitkan dengan pendataan dan verifikasi Barang Milik Negara, berbasis Address Ecological dikaitkan dengan permasalahan adaptasi perubahan iklim. Hasil pembaruan dapat dimanfaatkan ketika Pemerintah Desa Pemagarsari bersama dengan Musyawarah Lembaga Pengembangan (Muslembang) dalam perencanaan dan kontrol pembangunan fisik berdasarkan Indeks Pembangunan Manusia (Human Development Index).

\section{Perbandingan data sekunder dan primer}

Perolehan data sekunder dan primer yang ditindaklanuti dengan perbandingan terhadap kedua data tersebut. Perbandingan data keseluruhan, seperti ditunjukkan pada Tabel 1. 
Tabel 1. Perbandingan Data Keseluruhan

\begin{tabular}{|c|c|c|c|c|c|c|}
\hline \multirow[b]{2}{*}{ No. } & \multicolumn{3}{|l|}{ Nama Sarana } & \multicolumn{3}{|c|}{ Jumlah Sarana } \\
\hline & $\begin{array}{l}\text { Profil Desa } \\
2017\end{array}$ & $\begin{array}{l}\text { Peta } \\
\text { Terdahulu }\end{array}$ & Peta 2017 & $\begin{array}{l}\text { Profil } \\
\text { Desa } 2017\end{array}$ & $\begin{array}{l}\text { Peta } \\
\text { Terdahulu }\end{array}$ & $\begin{array}{l}\text { Peta } \\
2017\end{array}$ \\
\hline$(1)$ & $(2)$ & $(3)$ & $(4)$ & $(5)$ & (6) & $(7)$ \\
\hline 1 & Masjid & Masjid & Masjid & 11 unit & 7 unit & 11 unit \\
\hline 2 & Mushola & Mushola & Mushola & 30 unit & 25 unit & 30 unit \\
\hline 3 & Gereja & - & - & - & - & - \\
\hline 4 & PAUD & - & PAUD & 10 unit & - & 6 unit \\
\hline 5 & SD & SD/MI & SD/MI & 5 unit & 3 unit & 6 unit \\
\hline 6 & SMP & SLTP & SMP/MTs. & 2 unit & 2 unit & 6 unit \\
\hline 7 & SMA & SLTA & SMA/MA & 2 unit & 4 unit & 2 unit \\
\hline 8 & Puskesmas & - & & 5 unit & - & \\
\hline 9 & Posyandu & Posyandu & & 9 unit & 6 unit & \\
\hline 10 & Warnet & - & & 5 unit & - & \\
\hline 11 & Kantor Pos & - & & 1 unit & - & \\
\hline 12 & $\begin{array}{l}\text { Tempat } \\
\text { Pemakaman } \\
\text { Umum }\end{array}$ & $\begin{array}{l}\text { Tempat } \\
\text { Pemakama } \\
\text { n Umum }\end{array}$ & $\begin{array}{l}\text { Tempat } \\
\text { Pemakama } \\
\text { n Umum }\end{array}$ & 5 lokasi & 5 lokasi & 5 lokasi \\
\hline 13 & - & $\begin{array}{l}\text { Kantor } \\
\text { Desa }\end{array}$ & $\begin{array}{l}\text { Kantor } \\
\text { Desa }\end{array}$ & - & 1 unit & 1 unit \\
\hline 14 & - & - & $\begin{array}{l}\text { Pondok } \\
\text { Pesantren }\end{array}$ & - & - & 3 unit \\
\hline 15 & - & - & $\begin{array}{l}\text { Mini } \\
\text { Market }\end{array}$ & - & - & 3 unit \\
\hline 16 & - & - & Peternakan & - & - & 3 unit \\
\hline 17 & - & - & $\begin{array}{l}\text { Rumah } \\
\text { Bersalin }\end{array}$ & - & - & 1 unit \\
\hline
\end{tabular}

Berdasarkan Tabel 1 dapat dijelaskan, bahwa nama dan jumlah sarana pada kolom Peta Terdahulu dengan yang ada pada kolom Peta 2017, ditemukan data yang sama maupun berbeda. Nama dan jumlah sarana, meliputi:

1) Nama sarana pada Peta Terdahulu sana dengan pada Peta 2017, yaitu terdapat empat penamaan yang mliputi Masjid, Mushola, Tenpat Pemakaman Umum, dan Kantor Desa;

2) Nama sarana pada Peta Terdahulu berbeda penamaan pada Peta 2017 sebanyak dua penamaan, yaitu SLTP dengan SMP/MTs, dan SLTA dengan SMA/MA;

3) Penamaan sarana pada Peta Terdahulu namun tidak terdapat pada Peta 2017 sebanyak satu penamaan, yaitu Posyandu;

4) Penamaan sarana yang ada pada namun tidak ada pada Peta 2017 dengan Peta Terdahulu sebanyak lima penamaan yaitu Paud, Pondok Pesantren, Mini market, Peternakan dan Rumah Bersalin; dan

5) Perbedaan jumlah sarana ada lima jenis sarana yaitu Masjid, Mushola, SD-SD/MI, SLTP-SMP/MTs, SLTA SMA/MA. 


\section{Bentuk Fisik Peta Sarana Desa Terbarui}

Proses pembaruan dan pembuatan hardcopy peta sarana desa ukuran A1 beserta bingkai

Berdasarkan hasil pengolahan data sekunder dan primer, maka dilakukan pembaruan Peta Sarana Desa Pemagarsari dengan aplikasi photoshop melalui musywarah seluruh anggota tim. Pembaruan dan pembuatan hardcopy peta sarana desa dilaksanakan melalui sejumlah tahapan proses, yaitu:

1) Disiapkan laptop dengan aplikasi photoshop dan dua mahasiswa yang berkoordinasi dalam pekerjaan pembaharuan peta sarana desa ini. Hasil pengolahan data sekunder dan primer disiapkan, agar dapat diperoleh kemudahan saat pemrosesan dengan aplikasi Photoshop;

2) Disiapkan satuan skala balok dengan praktik satu objek ke objek lain dengan berpedoman kepada dashboard jarak (dalam kilometer) di sepeda motor. Besaran kesalahan yang diizinkan sekitar dua meter;

3) Diaktifkan aplikasi photoshop dengan lembar kerja format A1, kemudian dibuat atribut dengan isi pada layer atribut;

4) Disisipkan hasil foto peta sarana desa yang terdapat di dinding Kantor Desa Pemagarsari pada layer peta lama;

5) Diperhatikan notasi gambar sarana desa pada peta sarana desa lama yang meliputi masjid, mushola, TPU, Kantor Desa, Posyandu, SD/MI, SMP/MTs., SMA/MA, PAUD, Pondok Pesantren, Rumah Sakit, Mini Market, dan Rumah Bersalin;

6) Diperhatikan notasi gambar batas administrasi jalan, yaitu batas lahan, batas desa, batas kecamatan, batas provinsi, juga jalan desa, jalan kabupaten, dan jalan provinsi;

7) Diperhatikan notasi warna pembeda wilayah kerja rukun warga, yaitu RW-1. RW-2, RW-3, RW-4, RW-5, dan RW-6;

8) Ketiga notasi teresbut di-cropp dan di-paste pada bagian keterangan;

9) Berdasarkan hasil pengamatan lapangan, maka ditambahkan atau dihilangkan materi yang ada;

10) Dilengkapi isi penjelasan atribut;

11) Dibuatkan file dalam format .pdf; dan

12) Dibuatkan harcopy dan dibingkai.

Penjadwalan dan penyerahan peta sarana desa terbarui secara simbolis ke Kepala Desa Pemagarsari

Hasil kegiatan pembaruan Peta Sarana Desa yang dijadwalkan pada acara penutupan KKN 2017 pada tanggal 7 September 2017 di Kantor Desa Pemagarsari. Tampilan peta sarana desa di Desa Pemagasari hasil pembaruan, seperti ditunjukkan pada Gambar 8. 


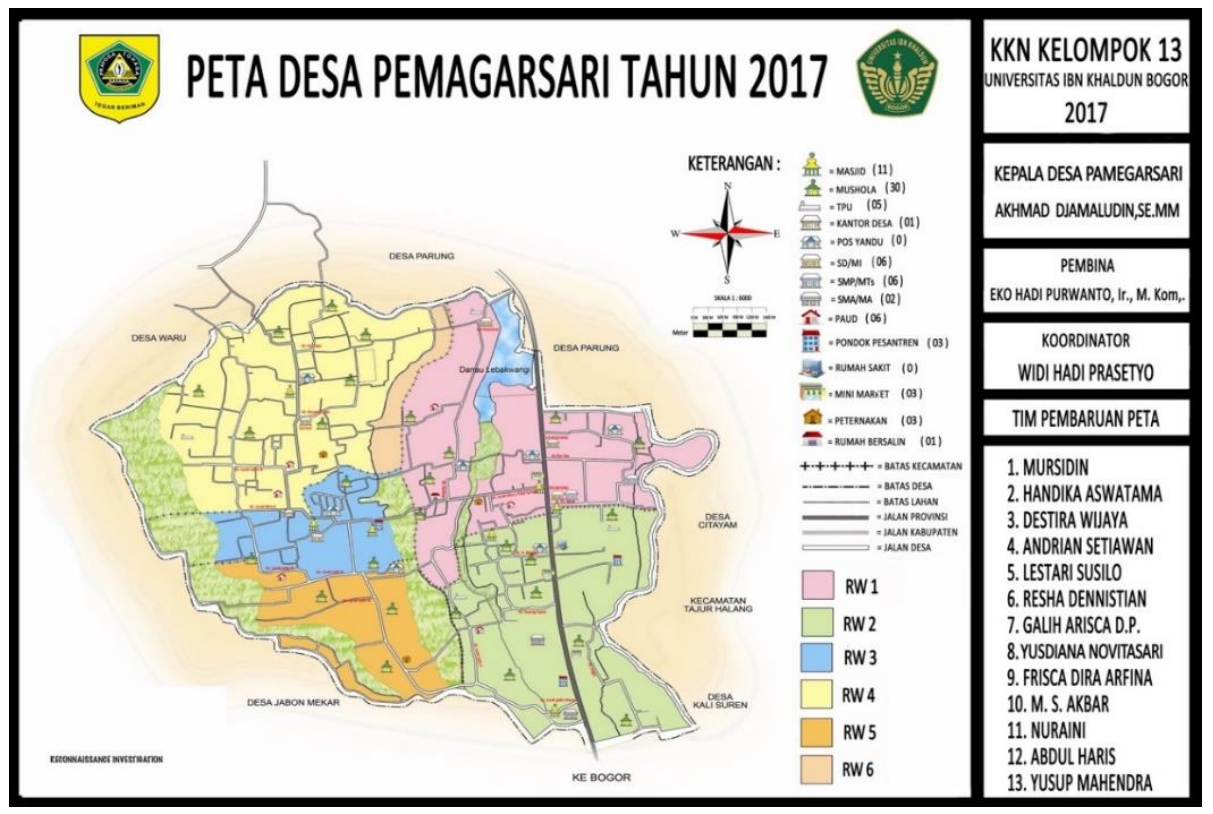

Gambar 8. Tampilan peta sarana desa di Desa Pemagarsari hasil pembaruan

Penyerahan peta sarana desa dilakukan pada tanggal 7 September 2017 bertempat di Kantor Desa Pemagarsari pada saat acara Penutupan Kegiatan KKN-TT UIKA tahun 2017. Penyerahan peta sarana desa diterima oleh Kepala Desa Pemagarsari dengan dihadiri sejumlah staf desa dan seluruh mahasiswa naggota kelompok 13 KKN-TT. Penyerahan peta sara desa hasil pembaharuan secara simbolis, seperti ditunjukkan pada Gambar 9.

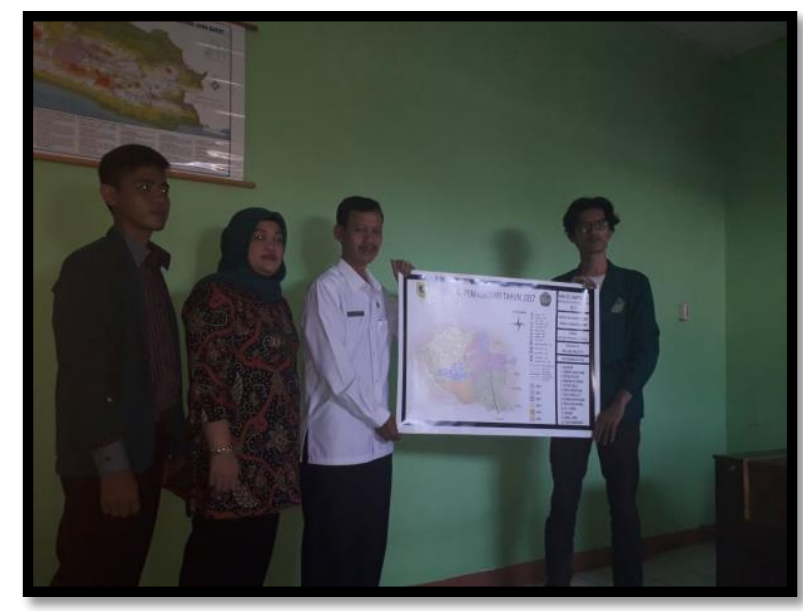

Gambar 9. Penyerahan peta sarana desa hasil pembaharuan secara simbolis

\section{SIMPULAN}

Sejumlah tahapan proses untuk pembaruan peta sarana desa untuk Desa Pemagarsari dilakukan melalui persiapan tim kerja, pengajuan izin pembaruan terhadap peta sarana desa, dan perbandingan data sekunder dan primer. Tim kerja terdiri atas sejumlah mahasiswa dari berbagai program studi (prodi). Proses pengajuan izin diawali 
dengan pembicaraan tentang gagasan pembaruan terhadap peta sarana desa yang ada. Perbandingan antara data sekunder dan primer ditekankan kepada nama dan jumlah sarana pada kolom peta yang ada di peta terdahulu dan peta 2017. Perolehan bentuk fisik peta sarana desa terbarui, dilakukan melalui proses pembaruan dan pembuatan hardcopy peta sarana desa ukuran kertas A1 beserta bingkai dan penjadwalan dan penyerahan peta sarana desa terbarui secara simbolis ke Kepala Desa Pemagarsari. Pembaruan dan pembuatan hardcopy peta sarana desa dilaksanakan melalui sejumlah tahapan proses, sedangkan hasil kegiatan pembaruan Peta Sarana Desa telah diserahterimakan pada acara penutupan KKN 2017, tanggal 7 September 2017 di Kantor Desa Pemagarsari dan diterima langsung oleh Kepala Desa Pemagarsari.

Peta sarana desa yang telah diperbarui ini merupakan pembaruan peta dengan topik fasilitas desa. Kegiatan ini merupakan kegiatan pendataan awal yang perlu verifikasi dan validasi menyeluruh dari instansi terkait berrdasarkan peta dasar yang diterbitlan oleh Badan Informasi Geospasial (BIG), yaitu Peta Rupa Bumi. Ketelitian pembuatan peta lanjutan dilakukan dengan implementasi terhadap aplikasi (software) berbasis Sistem Informasi Geografis (Geographic Information System, GIS), salah satunya ArcGIS.

\section{REFERENSI}

Applegate, L. M., Cash Jr, J. I., \& Mills, D. Q. (1988). Information technology and tomorrow's manager, in Harvard Business Review. Watertown, Massachusetts: Harvard Business Publishing, Harvard University.

Diskominfo Kabupaten Bogor. (2014). Desa Pamager Sari; Profil desa. Retrieved May 1, 2019 from https://kecamatanparung.bogorkab.go.id/desa/208

Goeritno, A., Risamasu, F., Widodo, I., Mustafril, Syaiful, M., Prastowo, Mudiastuti, S., Suhatmono, \& Yahyah. (2003). Konsep penerapan teknologi tepat guna sebagai alternatif upaya mengatasi dampak kerusakan sumberdaya air (Concept of application of applied technology as an alternative in working out the effects of water resource damage). Retrieved May 1, 2019 from http://www.rudyct.com/PPS702-ipb/07134/71034_6.pdf.

Hikmat, R. H. (2001). Strategi pemberdayaan masyarakat. Bandung: Humaniora Utama Press (HUP).

Leavitt, H., \& Whisler, T. (1958). Management in the 1980's, in Harvard Business Review. Watertown, Massachusetts: Harvard Business Publishing, Harvard University.

Longley, D., \& Shain, M. (1988). Dictionary of information technology. London: Macmillan International Higher Education.

Peraturan Pemerıntah Nomor 8 Tahun 2013, tentang Ketelitian Peta Rencana Tata Ruang, tanggal 2 Januari 2013.

Pusat Bahasa Departemen Pendidikan Nasional. (2008). Kamus Bahasa Indonesia. Jakarta: Balai Pustaka. 
Simpson, J. A., \& Weiner, E. S. C. (1989). The Oxford English Dictionary, Second edition. New York: Oxford University Press.

Undang-Undang Republık Indonesıa Nomor 4 Tahun 2011, tentang Informasi Geospasial, tanggal 21 April 2011.

William, B. K., \& Sawyer, S. C. (2014). Using information technology: a Practical introduction to computers \& communication, 9th edition (Complete Version). New York, NY: McGraw-Hill. 